\title{
Design of a Virtual Environment Applied to Social Phobias to reduce the Treatment time in Patients
}

\author{
Alexi Delgado ${ }^{1}$, Enrique Lee Huamaní ${ }^{2}$, Lucas Vega ${ }^{3}$ \\ ${ }^{1}$ Mining Engineering Section, Pontificia Universidad Católica del Perú, Lima, Perú \\ ${ }^{2}$ Image Processing Research Laboratory, Universidad de Ciencias y Humanidades Lima, Perú \\ ${ }^{3}$ Systems Engineering Program, Universidad de Ciencias y Humanidades, Lima, Perú
}

\begin{abstract}
People who suffer from social phobia, when they speak in public, have feelings of nervousness, anxiety and panic as well as experiencing it at different times in their daily lives such as at work, school, university, among others. In this work the methodology of the planning treatments was implemented. In this case study, programs were used for design and development such as Google Sketchup, Blender, and VrmlPad. The results of the virtual world design together with the methodology that was used helped to make comparisons of a different virtual world used to other needs. The development of the virtual world implemented in health clinics in Lima will help patients with social phobias of the non-generalized type, because employing the Virtual Reality treatment contributes to the improvement of the patient and in turn allows us to achieve results in a few periods of time.
\end{abstract}

Key words: Social Phobia, Virtual World, Virtual Reality, Virtual Reality Treatment.

\section{INTRODUCTION}

Social anxiety disorders or as it is also known as social phobia, are the symptoms that people suffer at the time of presenting a social situation, which causes the person to panic or despair, in addition there are 2 types of social phobia, the first is the non-generalized type, in which people normally exhibit performance anxiety and have feelings of fear when speaking in front of large groups, the second is the generalized type, people suffer from this disorder, because they have a fear persistent and avoidance of most social situations [1]. Peru does not get rid of this disease in regards to MINSA (Ministry of Health) in 2018, 7\% of the population suffers from anxiety, which is directly linked to the phobia [2]. While in adolescents according to the National Institute of Mental Health they suffer more frequently mental disorders obtaining $7.1 \%$ in Lima and Callao of social phobia compared to the other regions of Peru [3].

The methodologies encountered for a better development of To treat social phobias, psychologists use somatic methods that include medications, and psychotherapeutic methods, such as supportive psychotherapy compared to Spanish clinics such as Psius and Previ that improve these treatments using Virtual Reality (VR), exposure to virtual reality It creates a greater sense of presence and is much more immersive. This is an important issue since the therapy aims to facilitate the emotional processing of patients to social situations [4]. With the support of VR technology, a 3D virtual world will be designed applying the Planning methodology of a methodological process for the creation of virtual environments [5], It is worth mentioning that the SENDA methodology was not used, which is a flexible framework that can be used for the life cycle of a Virtual Environments (VE) or only for a set of Processes [6]. Compared to the methodology used, SENDA does not have a testing stage as it is necessary to know if the virtual environment is functioning in an optimal state.

Clinics specializing in mental health control use different techniques and treatments such as SET-C is a multifaceted behavior treatment modeled from a successful program used for adults with social phobia [7], that is why it will be implemented in the Lima clinics, devices such as HMD are the virtual reality (VR) head mounted screens (HMD) which allows us to create a highly immersive experience [8], that will allow the patient to interact with the virtual world, which in this case will be a scenario where the patient will face his fear of speaking in public with certain hours of sessions per day.

The general objective of this research work is to strengthen my research knowledge, as well as the topics discussed (social phobia and RV), to design an RV environment that will improve the treatment of social phobias and thus achieve better results in a short time frame.

The research work will be divided into 5 parts, in the first stage: The introduction, in the second stage the methodology will be used, in the third stage: The case study, in the fourth stage: Results and discussions, the fifth stage: The conclusions, where the answers to the proposed research objectives will be found.

\section{METHODOLOGY}

For this investigation the methodology of the planning of a methodological process for the creation of virtual 
environments will be applied [5], the structure of this methodology will allow the design, as well as the development of the virtual environment, as shown in Figure 1.

\subsection{Space selection and prior study}

In this first stage, the scenario to be created will be specified, in addition to all the essential characteristics that the environment will have, as well as its restrictions and scope, through the help of a form.

\subsection{Planning of the Virtual Environment Creation Project}

At this stage it will be decided the tasks and the time it will take to perform them, as well as specifying what it will take for the creation of the virtual world through the help of the schedule of activities.

\subsection{Obtaining Requirements}

At this stage the functional and non-functional requirements that are desired for the virtual world will be carried out with the help of the client's participation, in this case the patient and also the psychologist.

\subsection{Design}

At this stage, the virtual world modeling design will be carried out with the help of the Google Sketchup program.

\section{A. Google Sketchup}

It is a 3D dynamic drawing software that is generally used to design 3D construction models [9].

\subsection{Model Development and Integration}

In this stage the virtual world model is developed based on the design that was made in the previous stage. The Blender tool that is open source will be implemented in addition to modeling, rendering and package animation software [10]. In addition to having VrmlPad: it is a standard file format to represent three-dimensional (3D) interactive vector graphics, [11] and the Cortona $3 \mathrm{~d}$ tool to visualize the virtual world with a web browser.

\subsection{Tests}

In this stage, the respective tests to the virtual world will be carried out in order to rule out any errors and defects that can be identified. The tests will focus on the design of 3D objects and test users (patients with social phobias), in addition to performing the tests, the virtual reality helmet VRShinecon will be needed.

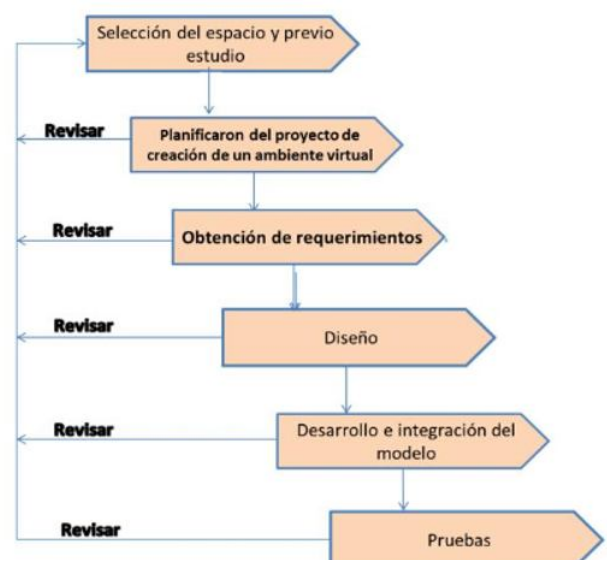

Figure 1: Methodology for creating virtual environments

\section{APPLICATION}

\subsection{Space selection and prior study}

The virtual environment was specified, as well as the objects it will contain and as can be seen in Table 1.

Table 1: Space Selection

\begin{tabular}{|c|c|c|c|}
\hline $\begin{array}{l}\text { Space } \\
\text { Name }\end{array}$ & $\begin{array}{l}\text { Stage for } \\
\text { speeches }\end{array}$ & $\begin{array}{l}\text { Type of } \\
\text { Objects }\end{array}$ & $\begin{array}{l}\text { Armchair patio, proportionally high } \\
\text { rectangular shaped scene, racks next } \\
\text { to the scene, podium, reflectors and } \\
\text { people created for the virtual } \\
\text { environment. }\end{array}$ \\
\hline Objective & \multicolumn{3}{|c|}{$\begin{array}{l}\text { The environment will be created to help people afraid to speak in } \\
\text { public. }\end{array}$} \\
\hline Scopes & \multicolumn{3}{|c|}{$\begin{array}{l}\text { The patient can interact with the environment as many times as } \\
\text { necessary. } \\
\text { People created for the environment will react well or badly } \\
\text { according to the circumstances of the case. } \\
\text { The patient will expose a certain topic for the virtual public so that it } \\
\text { manages to function. } \\
\text { People created in the virtual world will interact with the patient at } \\
\text { the end of the exhibition. }\end{array}$} \\
\hline Limits & \multicolumn{3}{|c|}{$\begin{array}{l}\text { A simple virtual environment will be created. } \\
\text { The design of people in the virtual environment will not be so } \\
\text { complex. }\end{array}$} \\
\hline
\end{tabular}

\subsection{Planning of the Virtual Environment Creation Project}

To establish the duration of the activities and the tasks to be performed, as well as their respective duration, a schedule of activities was developed as shown in Figure 2.

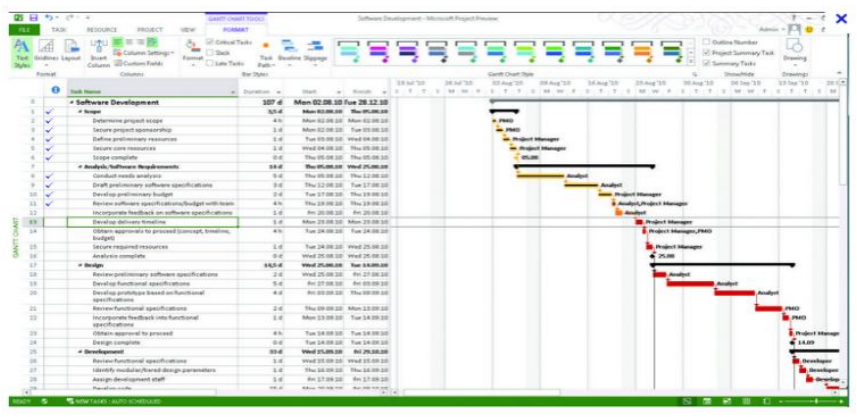

Figure 2: Schedule of activities.

\subsection{Obtaining Requirements}

Tables of functional and non-functional requirements of the virtual environment were made as shown in Table 2 and Table 3. 
Table 2: Requirements

\begin{tabular}{|c|c|c|}
\hline Number & Requirement & Description \\
\hline $\mathrm{RF}-01$ & $\begin{array}{l}\text { Interact with the } \\
\text { virtual environment }\end{array}$ & $\begin{array}{l}\text { The user can interact in a limited } \\
\text { way with the virtual environment. }\end{array}$ \\
\hline RF-02 & Take the defined route & $\begin{array}{l}\text { The user will be in a defined } \\
\text { place, he will not be able to } \\
\text { choose the place he wishes to } \\
\text { visit. }\end{array}$ \\
\hline RF-03 & React to the user & $\begin{array}{l}\text { people created in the virtual world } \\
\text { will react to the user. }\end{array}$ \\
\hline RF-04 & $\begin{array}{l}\text { Develop virtual } \\
\text { objects with a simple } \\
\text { level of detail. }\end{array}$ & $\begin{array}{l}\text { The detail of virtual objects will } \\
\text { be based on a simple environment. }\end{array}$ \\
\hline RF-05 & $\begin{array}{l}\text { Develop dynamic and } \\
\text { static objects }\end{array}$ & $\begin{array}{l}\text { The objects for the virtual } \\
\text { environment will vary between } \\
\text { dynamic and static, for interaction } \\
\text { with the user. }\end{array}$ \\
\hline
\end{tabular}

Table 3:. Non-Functional Requirements

\begin{tabular}{|l|l|l|}
\hline Number & Requirement & Description \\
\hline RNF-01 & $\begin{array}{l}\text { Implement the virtual } \\
\text { world on a device }\end{array}$ & $\begin{array}{l}\text { The virtual environment will } \\
\text { be implemented on a } \\
\text { Shinecon G04E VR device. }\end{array}$ \\
\hline RNF-02 & Portability & $\begin{array}{l}\text { The virtual environment will } \\
\text { provide comfort to the user. }\end{array}$ \\
\hline RNF-03 & Usability & $\begin{array}{l}\text { The virtual environment will } \\
\text { allow easy use. }\end{array}$ \\
\hline
\end{tabular}

\subsection{Design}

At this stage the Google Sketchup design tool will be implemented which will allow us to design the virtual world as shown in Figure 3.

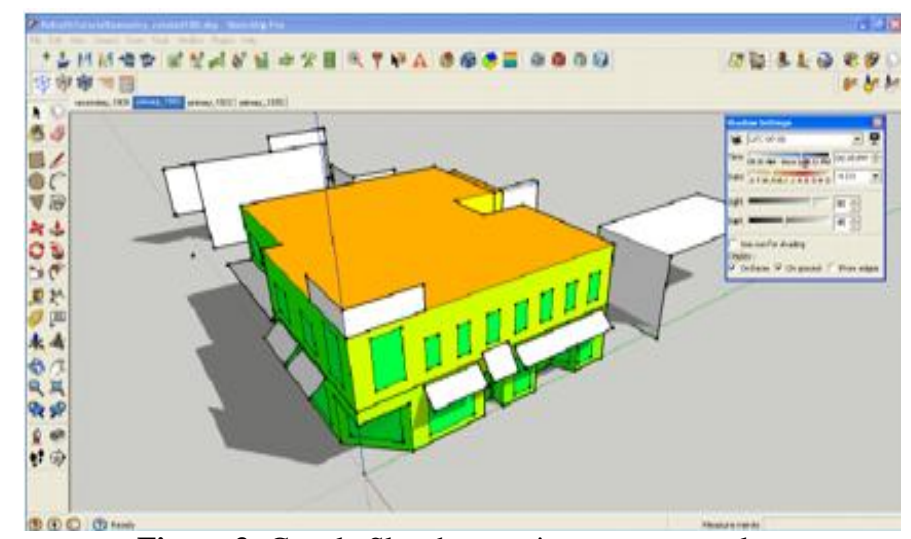

Figure 3: Google Sketchup environment example

\subsection{Model Development and Integration}

For the development, the Blender tool will be used to give a better 3D design to the objects on the stage as shown in Figure 4, then the VmdlPad tool will be used to develop the virtual world, and finally will use Cortona $3 \mathrm{D}$, to be able to visualize the virtual environment on the web.

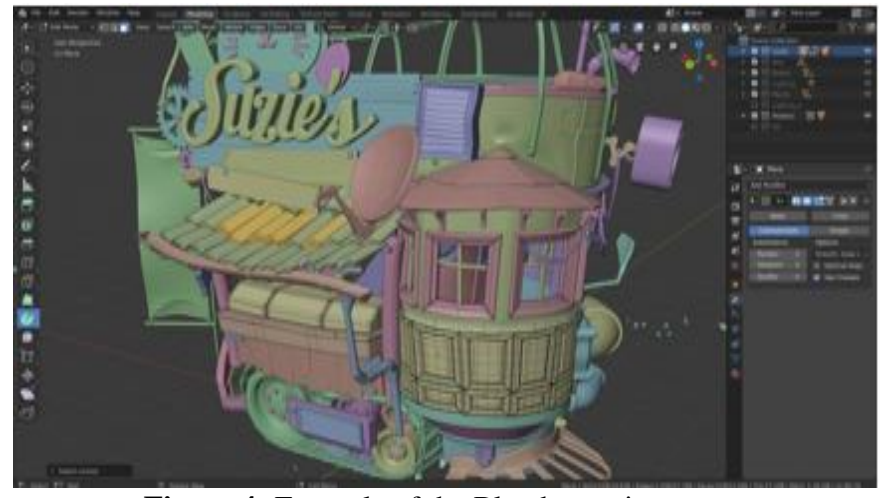

Figure 4: Example of the Blender environment

\subsection{Tests}

For the testing stage, it will be verified with the help of a person who will test the virtual environment with the help of the VRShinecon [12] as shown in Figure 5.

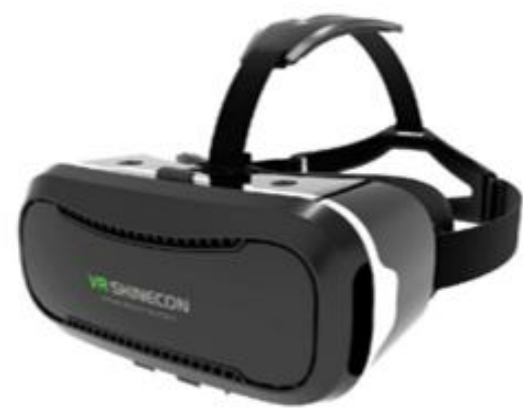

Figure 5: VRShinecon object

\section{RESULTS AND DISCUSSION}

\subsection{About the Application}

In the case study, the design of the web system was achieved with a Chat Bot, especially to apply it to the detection of diabetes with Machine Learning. In the design of Figure 6, you can flow the future functionality that the Chat Bot will have.

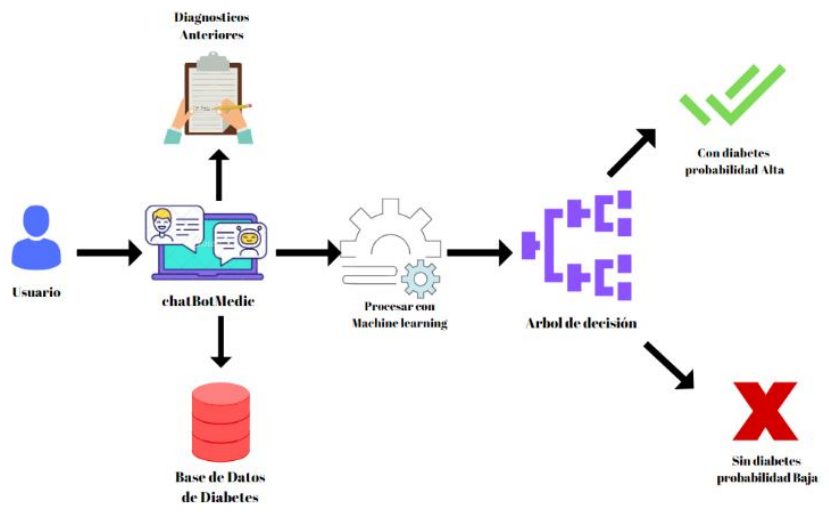

Figure 6: Software flow 
In the case of this research work, only one person with social phobia of 16 sessions will be carried out during the 4 months, with a duration of approximately $1 \mathrm{~h}$ each session, where the therapist will observe the treatment process through a monitor[13].

In this project if there is a defined methodology, although little known that will help to define well the processes that will be implemented, divided into different stages and the use of different design and programming tools such as Blender and VrmlPad. Unlike the virtual world presented in the magazine which resembles a room with people sitting in front of you, for this work there was a stage similar to a theater where the patient will have to present a topic in front of an audience, and these they will react positively or negatively depending on the interaction of the patient[14].

\subsection{Comparison of the RV in another Phobia}

In the research work The virtual reality treatment of phobia to fly, they have 4 people who suffered different traumas throughout their lives, to help them it was decided to opt for the Virtual Reality treatment, using development tools such as Sense's WorldUp8 Corp, and with the help of these tools such as DIVE, 3 scenarios were created: a room in which travel bags are placed, the boarding room and inside the plane. 8 treatment meetings were held where the virtual reality exposure sessions lasted approximately $35-45 \mathrm{~min}$, a monitor allowed the therapist to observe the VE to which the participants were exposed [15][16][17].

In the case of this research work, only one person with social phobia of 16 sessions will be carried out during the 4 months, with a duration of approximately $1 \mathrm{~h}$ each session, where the therapist will observe the treatment process through a monitor

\section{CONCLUSIONS}

To implement the environment of a virtual reality scenario, the Cortona 3D program is being used to visualize the virtual environment with the help of an HMD such as VRShinecon to achieve a better immersion, so the Lima clinics specialized in mental treatments will opt for choosing RV treatment by implementing it with patients with social phobias.

The methodology used, although little known, was used for the structure that is divided into 7 stages, necessary to make an adequate description of the information, design, development and testing of the virtual world, as well as the correct use of resources such as time and money used, stages that methodologies such as SENDA do not count.

For future projects it is recommended to develop the design proposed in this methodology, as well as to implement different methodologies that have not been mentioned in this research work for the development of RV environments.

\section{REFERENCES}

1. C. Chiao and C.-H. Chiu, "The relationships between ICT use and life quality among children with social phobia," in 2016 IEEE International Conference on Teaching, Assessment, and Learning for Engineering (TALE), 2016, pp. 26-31. https://doi.org/10.1109/TALE.2016.7851765

2. "\&quot;La fobia más frecuente es la social\&quot; aseguró experto del Minsa | Diario Correo." [Online]. Available:

https://diariocorreo.pe/edicion/lima/la-fobia-mas-frecuen te-es-la-social-segun-especialista-del-minsa-817629/.

[Accessed: 09-Sep-2019].

3. Ministerio de Salud, "PROGRAMA PRESUPUESTAL CONTROL Y PREVENCION EN SALUD MENTAL."

[Online].

Available:

http://www.saludarequipa.gob.pe/archivos/definicioneso peracionales/Definiciones Operacionales Salud Mental.pdf. [Accessed: 09-Sep-2019].

4. R. M. Banos et al., "Virtual reality treatment of flying phobia," IEEE Trans. Inf. Technol. Biomed., vol. 6, no. 3, pp. 206-212, Sep. 2002.

5. I. Castaño, "Metodologia para el desarrollo de Ambientes Virtuales by idelson castao - issuu," 2012.

6. M. I. Sánchez-Segura, J. J. Cuadrado, A. de Antonio, A. de Amescua, and L. García, "Adapting traditional software processes to virtual environments development," Softw. Pract. Exp., vol. 33, no. 11, pp. 1051-1080, Sep. 2003.

7. D. C. Beidel, S. M. Turner, and T. L. Morris, "Behavioral treatment of childhood social phobia.," J. Consult. Clin. Psychol., vol. 68, no. 6, pp. 1072-1080, 2000. https://doi.org/10.1037/0022-006X.68.6.1072

8. J. Gugenheimer, E. Stemasov, J. Frommel, and E. Rukzio, "A Demonstration of ShareVR: Co-Located Experiences for Virtual Reality Between HMD and Non-HMD Users," in 2018 IEEE Conference on Virtual Reality and 3D User Interfaces (VR), 2018, pp. 755-756.

9. A. Kurtulus and C. Uygan, "The effects of Google Sketchup based geometry activities and projects on spatial visualization ability of student mathematics teachers," Procedia - Soc. Behav. Sci., vol. 9, pp. 384-389, Jan. 2010.

10. M. Bailey and C. Law, "A Summer Blender Camp: Modeling, Rendering, and Animation for High School Students," IEEE Comput. Graph. Appl., vol. 34, no. 1, pp. 65-67, Jan. 2014.

11. D. Cheng and Y. Peng, "Study in interactive Virtual Campus based on VRML," in 2010 International Conference on Computer Application and System Modeling (ICCASM 2010), 2010, pp. V4-526-V4-529.

12. Z. Mohamed Elias, U. M. Batumalai, and A. N. H. Azmi, "Virtual reality games on accommodation and convergence," Appl. Ergon., vol. 81, p. 102879, Nov. 2019. https://doi.org/10.1016/j.apergo.2019.102879

13. U. De Oviedo, E. Olivares Rodríguez, J. ; Alcázar, A. Isabel, R.; Piqueras Rodríguez, and J. Antonio, 
"Detección temprana y tratamiento de adolescentes con fobia social generalizada," 2005.

14. M. Bruce and H. Regenbrecht, "A virtual reality claustrophobia therapy system - implementation and test," in Proceedings - IEEE Virtual Reality, 2009, pp. 179-182.

15. M. Slater, D.-P. Pertaub, and A. Steed, "Public speaking in virtual reality: facing an audience of avatars," IEEE Comput. Graph. Appl., vol. 19, no. 2, pp. 6-9, 199 https://doi.org/10.1109/38.749116

16. A. Delgado, P. Montellanos, and J. Llave, Air quality level assessment in Lima city using the grey clustering method,IEEE ICA-ACCA 2018 - IEEE International Conference on Automation/23rd Congress of the Chilean Association of Automatic Control: Towards an Industry 4.0 - Proceedings, 8609699, 2019. https://doi.org/10.1109/ICA-ACCA.2018.8609699

17. A. Delgado, and I. Romero, Applying the Grey Systems Theory to Assess Social Impact from an Energy Project, Proceedings of the 2018 IEEE 25th International Conference on Electronics, Electrical Engineering and Computing, INTERCON 2018, 8526372, 2018.

https://doi.org/10.1109/INTERCON.2018.8526372 